\title{
Wing morphometric variability in Aedes aegypti (Diptera: Culicidae) from different urban built environments
}

Ramon Wilk-da-Silva ${ }^{1}$, Morgana Michele Cavalcanti de Souza Leal Diniz ${ }^{1}$, Mauro Toledo Marrelli ${ }^{*}$ and André Barretto Bruno Wilke ${ }^{1,2}$

\begin{abstract}
Background: Aedes aegypti is the main vector of the dengue, Zika and several other arboviruses. It is highly adapted to urbanized environments and can be found worldwide. Mosquito population control is considered the best strategy for fighting mosquito-borne diseases, making an understanding of their population dynamics vital for the development of more effective vector control programs. This study therefore sought to investigate how different levels of urbanization affect Aedes aegypti populations and modulate population structure in this species with the aid of wing geometric morphometrics.
\end{abstract}

Methods: Specimens were collected from eleven locations in three areas with distinct levels of urbanization in the city of São Paulo, Brazil: conserved, intermediate and urbanized. The right wings of female mosquitoes collected were removed, and photographed and digitized. Canonical variate analysis and Mahalanobis distance were used to investigate the degree of wing-shape dissimilarity among populations. Thin-plate splines were calculated by regression analysis of Canonical Variation Analysis scores against wing-shape variation, and a crossvalidated reclassification was performed for each individual; a neighbor-joining tree was then constructed.

Results: Metapopulation and individual population analysis showed a clear segregation pattern in the Canonical Variation Analysis. Pairwise cross-validated reclassification yielded relatively high scores considering the microgeographical scale of the study and the fact that the study populations belong to the same species. The neighbor-joining tree showed that mosquitoes in the intermediate urban area segregated in the metapopulation and individual population analyses. Our findings show significant population structuring in Aedes aegypti mosquitoes in the areas studied. This is related to the different degrees of urbanization in the areas where the specimens were collected along with their geographical location.

Conclusions: Urbanization processes in the study areas appear to play an important role in microevolutionary processes triggered by man-made modifications in the environment, resulting in a previously unknown population structuring pattern of major epidemiological importance.

Keywords: Wing geometric morphometrics, Urbanization, Dengue, Aedes aegypti

\footnotetext{
* Correspondence: mmarelli@usp.br

'Departamento de Epidemiologia, Faculdade de Saúde Pública, Universidade

de São Paulo, São Paulo, Brazil

Full list of author information is available at the end of the article
}

(c) The Author(s). 2018 Open Access This article is distributed under the terms of the Creative Commons Attribution 4.0 International License (http://creativecommons.org/licenses/by/4.0/), which permits unrestricted use, distribution, and reproduction in any medium, provided you give appropriate credit to the original author(s) and the source, provide a link to the Creative Commons license, and indicate if changes were made. The Creative Commons Public Domain Dedication waiver (http://creativecommons.org/publicdomain/zero/1.0/) applies to the data made available in this article, unless otherwise stated. 


\section{Background}

Dengue fever is considered the most common mosquitoborne disease in the world. An estimated 3.9 billion people are at risk of infection, and there have been 390 million cases reported annually, primarily in tropical and subtropical regions [1-3]. The main vector of the disease is Aedes (Stegomyia) aegypti (Linnaeus), a mosquito with a worldwide distribution that is highly adapted to urbanized environments [4, 5]. It is also responsible for transmission of several other epidemiologically important arboviruses such as yellow fever virus, chikungunya virus and Zika virus [6-12].

Aedes aegypti can complete its entire life-cycle within a single household, using artificial breeding sites and blood-feeding on human hosts [13-15]. Moreover, man-made changes to the environment benefit it, as an increase in population density and the number of artificial breeding sites have been shown to be directly associated with a high abundance of this mosquito in urban areas [16-19]. The great abundance of Ae. aegypti mosquitoes, together with the multiple bloodfeeding behavior of females, tend to increase host-vector interaction, in turn increasing the dissemination of pathogens [20, 21].

Mosquito population control is considered the best strategy for fighting mosquito-borne diseases, making an understanding of Ae aegypti population dynamics vital for the development of more effective vector control programs. Population genetics studies provide important information about how mosquitoes react to selective pressures. One technique used in this type of study is wing geometric morphometrics based on quantitative analysis of wing venation characters, which has proved sensitive enough to detect fine-scale structuring on a microgeographical scale [22, 23]. The technique has been widely used in taxonomic and phylogenetic studies on micro- and macrogeographical scales [24-28].

Several studies using wing geometric morphometrics indicate that urbanization processes may have been modulating mosquito population dynamics [22, $25,28,29]$, leading to population structuring. This is clearly relevant to disease epidemiology, since population structuring can influence the dynamics of disease transmission. As variation in wing shape is modulated by genes, and is therefore less susceptible to selective pressures when compared with variation in wing size [30], geometric morphometric analysis of wing shape can be used to study mosquito population dynamics.

Our hypothesis is that Ae. aegypti is adapting locally to different urban build environments, and that wing geometric morphometrics may be able to provide important information about the population dynamics and population structuring of this species. The present study sought to use this technique to investigate how $A e$. aegypti populations are structured in the city of São Paulo and how their interaction with areas with different levels of urbanization can modulate this structure [31-33].

\section{Methods}

\section{Specimen collection}

Aedes aegypti mosquitoes were collected in eleven areas, no more than $30 \mathrm{~km}$ apart with three distinct levels of urbanization in the city of São Paulo, Brazil (Fig. 1, Table 1).

Conserved areas $(\mathrm{CON})$ : five municipal parks (large green areas) open to the public from 5:00 to 20:00 h. No chemical or biological control measures are used in the parks. The wild fauna includes birds, reptiles and mammals.

Intermediate areas (INT): four collection sites on the University of São Paulo Armando de Salles Oliveira campus. The campus covers $3,648,944.40 \mathrm{~m}^{2}$, of which approximately $800,000 \mathrm{~m}^{2}$ has been built on. More than 100,000 people visit, pass through or study or work on the campus every day.

Urbanized areas (URB): two collection sites on the University of São Paulo health sciences campus. This is in a highly urbanized, densely populated area and extends over $83,050.82 \mathrm{~m}^{2}$, of which $79,923.72 \mathrm{~m}^{2}$ has been built on (Table 1).

Mosquitoes were collected between 2012 and 2015 . Adult specimens were collected with portable battery-powered aspirators [34], and immature mosquitoes were collected using different collection tools (Additional file 1: Table S1). In the areas where the ovitraps were used, traps were put in shaded areas at least 50 meters apart, each with $500 \mathrm{ml}$ of water and hay infusion. The immature forms were kept under laboratory conditions and fed with fish food (Tetra BettaMin, Melle, Germany) until they reached adulthood. All mosquitoes collected were identified using taxonomic keys by Forattini [14] and stored in silica gel until the wings were removed. For this study, all specimens were collected during larval stages except for the population collected at Previdencia Park (CON-5), in which only adult mosquitoes were collected. Specimens were randomly selected to avoid testing siblings.

\section{Wing preparation and data acquisition}

The right wing of each female mosquito was removed, mounted on a microscope slide with a cover slip and photographed at a magnification of $45 \times$ with a Leica DFC320 digital camera coupled to a Leica S6 microscope. Eighteen landmarks were digitized on each wing image by one of the authors (RWS) using TpsDig (v.1.40) [35], following Louise et al. [22]. The selection of landmarks was 


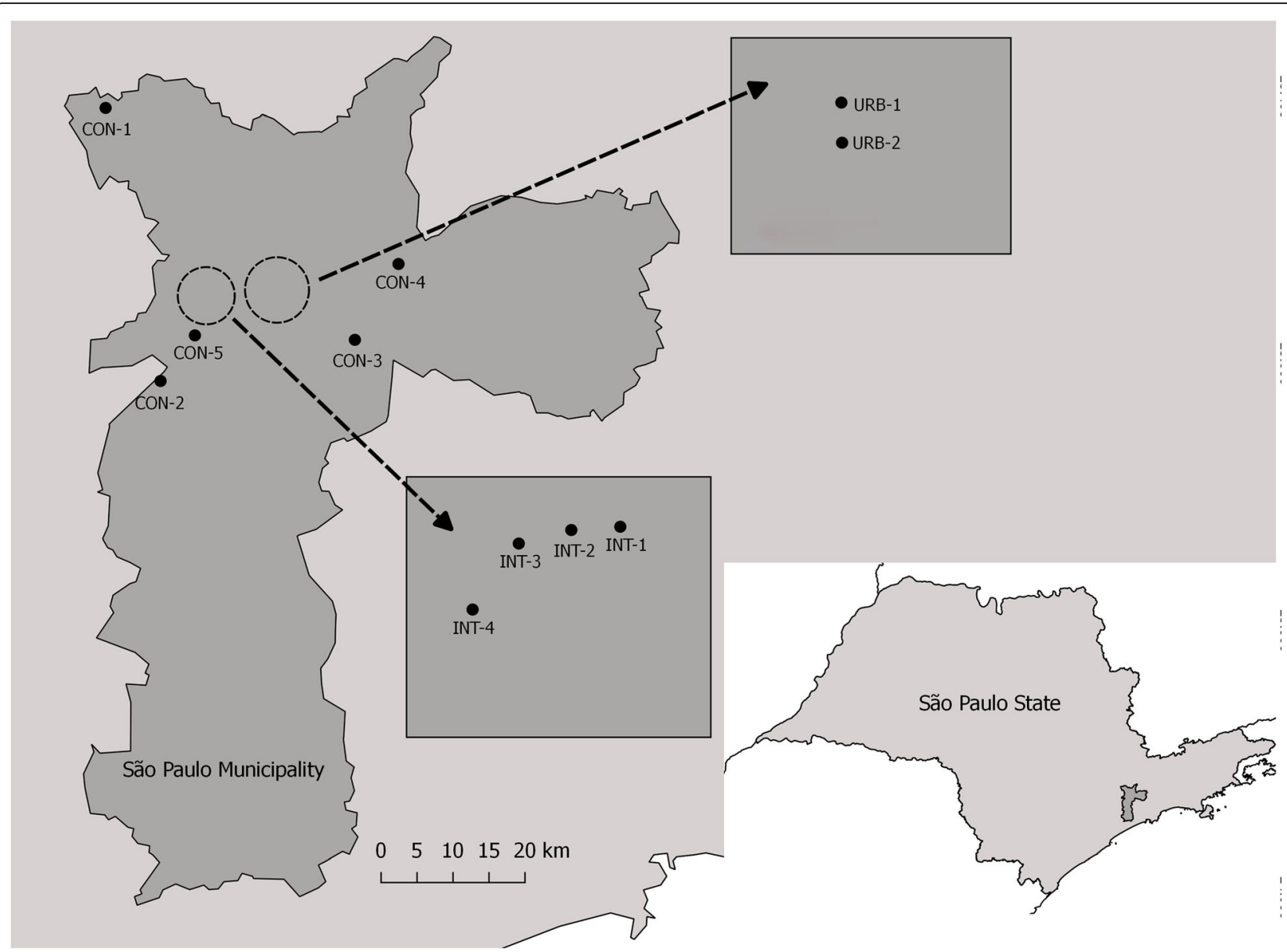

Fig. 1 Aedes aegypti sampling locations in the city of São Paulo, Brazil

based on wing venation intersection as follows: 1st, intersections of veins Radius + Radial sector; 2nd, Costa + Sub-costa; 3rd, Radius 1; 4th, Radius 2; 5th, Radius 3; 6th, Radius 4+5; 7th, Media 1; 8th, Media 2; 9th, Media 3+4; 10th, Cubitus anterior; 11th, Mediocubital crossvein +
Cubital anterior; 12th, Mediocubital + Media 3+4; 13th, Media + Media 1+2; 14th, Radiomedial crossvein + Media $1+2$; 15th, Radiomedial crossvein + Radius 4+5; 16th, Radial sector + Radius $2+3 ; 17$ th, Radius $2+3+$ Radius 2 and 3; 18th, Media 1+2 + Media 1 and 2 [36].

Table 1 Aedes aegypti collection sites and collection data

\begin{tabular}{|c|c|c|c|c|c|}
\hline Collection site & Code & Coordinates & Stage & $n$ & Year \\
\hline Anhanguera Park & $\mathrm{CON}-1$ & $23^{\circ} 24^{\prime} 54^{\prime \prime S}, 46^{\circ} 47^{\prime} 6^{\prime \prime} \mathrm{W}$ & Immature & 13 & 2013 \\
\hline Eucalipto Park & $\mathrm{CON}-2$ & $23^{\circ} 36^{\prime} 54^{\prime \prime} S, 46^{\circ} 45^{\prime} 18^{\prime \prime} \mathrm{W}$ & Immature & 30 & 2012 \\
\hline Independência Park & $\mathrm{CON}-3$ & $26^{\circ} 35^{\prime} 6^{\prime \prime} \mathrm{S}, 46^{\circ} 36^{\prime} 18^{\prime \prime} \mathrm{W}$ & Immature & 26 & 2015 \\
\hline Piqueri Park & $\mathrm{CON}-4$ & $23^{\circ} 31^{\prime} 30^{\prime \prime S}, 46^{\circ} 35^{\prime} 30 " \mathrm{~W}$ & Immature & 30 & 2013 \\
\hline Previdência Park & CON-5 & $23^{\circ} 35^{\prime} 6^{\prime \prime S}, 46^{\circ} 43^{\prime} 30^{\prime \prime} \mathrm{W}$ & Adult & 30 & 2015 \\
\hline University of São Paulo Student Accommodation & INT-1 & $23^{\circ} 33^{\prime} 18^{\prime \prime S}, 46^{\circ} 43^{\prime} 30^{\prime \prime} \mathrm{W}$ & Immature & 30 & 2014 \\
\hline Communication and Art School & INT-2 & $23^{\circ} 33^{\prime} 18^{\prime \prime S}, 46^{\circ} 43^{\prime} 30^{\prime \prime} \mathrm{W}$ & Immature & 29 & 2014 \\
\hline Physics Institute & INT-3 & $23^{\circ} 33^{\prime} 54^{\prime \prime} \mathrm{S}, 46^{\circ} 44^{\prime} 6^{\prime \prime} \mathrm{W}$ & Immature & 30 & 2014 \\
\hline Veterinary School & INT-4 & $23^{\circ} 33^{\prime} 54^{\prime \prime S}, 46^{\circ} 44^{\prime} 6^{\prime \prime} \mathrm{W}$ & Immature & 29 & 2014 \\
\hline Public Health School & URB-1 & $23^{\circ} 33^{\prime} 18^{\prime \prime} \mathrm{S}, 46^{\circ} 40^{\prime} 30^{\prime \prime} \mathrm{W}$ & Immature & 30 & 2015 \\
\hline Medicine School & URB-2 & $23^{\circ} 33^{\prime} 18^{\prime \prime} \mathrm{S}, 46^{\circ} 40^{\prime} 30^{\prime \prime} \mathrm{W}$ & Immature & 30 & 2015 \\
\hline
\end{tabular}



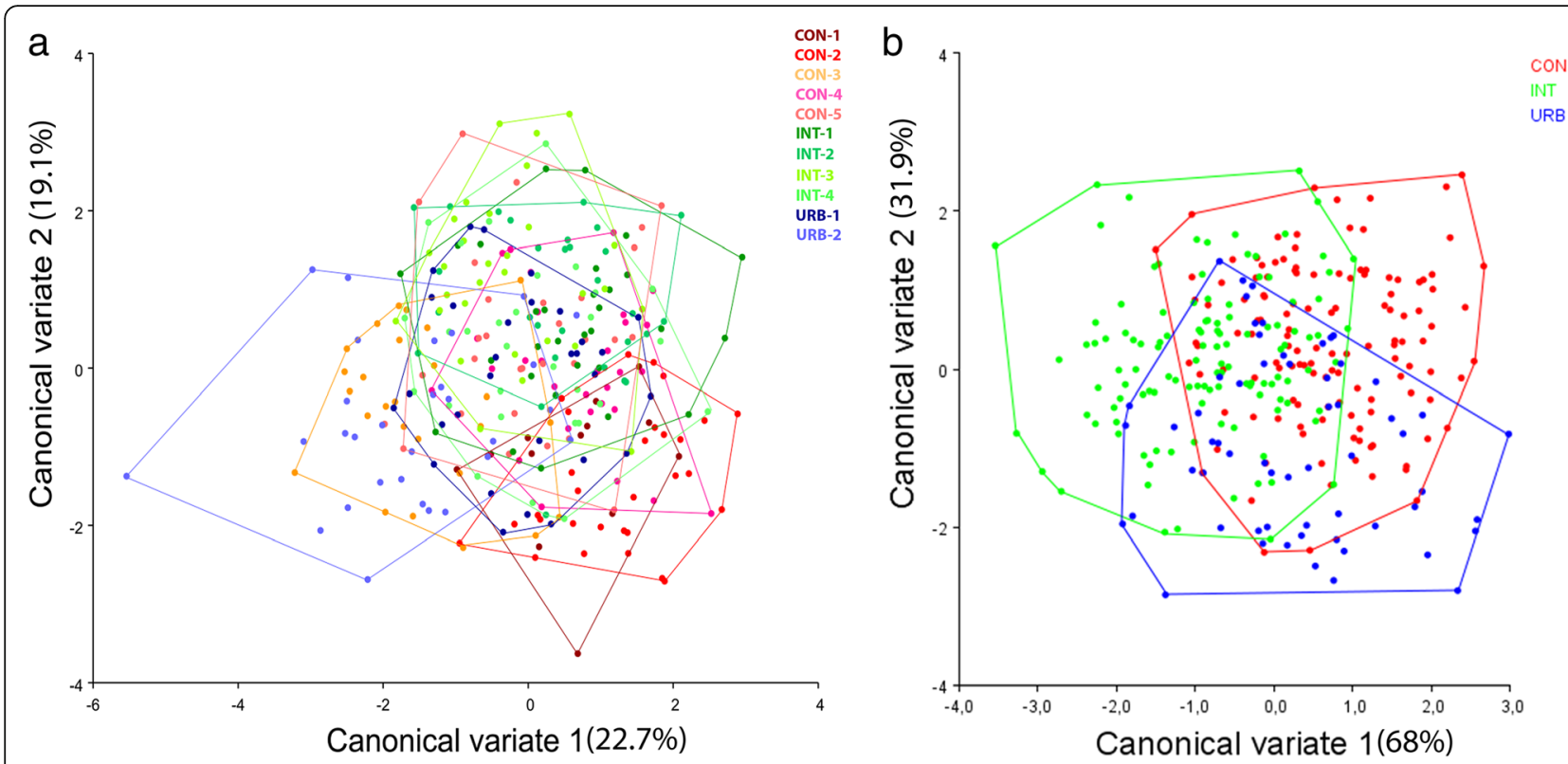

Fig. 2 Morphological space produced by CVA of Aedes aegypti based on collection sites (a) and urban build environments (b)

\section{Geometric morphometric analysis}

Procrustes coordinates referent to wing shape were obtained through the superimposition of landmark coordinates. Multivariate regression of the Procrustes coordinates against centroid size $(10,000$ randomizations) was used to assess the allometric influence of wing size on wing shape. Canonical variate analysis (CVA) was applied and the Mahalanobis distances calculated to investigate the degree of dissimilarity in wing shape between the study populations. To visualize shape disparity, thin-plate splines were generated by regression analysis of CVA scores against wing-shape variation. Cross-validated reclassification based on the
Mahalanobis distance was carried out for each individual, consisting on the blinded reclassification of each specimen taking into account only the variations in wing shape, thereby making it possible to identify levels of similarity in wing shape between populations. A Neighbor-Joining (NJ) tree was constructed with 1000 bootstrap replicates to illustrate the patterns of variation among the populations (27 specimens of $A e$. albopictus were used as outgroup), and an UPGMA dendrogram was also constructed based on geographical distances between collection sites (Additional file 2: Figure S2). The analyses were carried out and graphs plotted with MorphoJ (v.2.0) [37] and PAST (v.3.16)

Table 2 Results of pairwise cross-validated species reclassification (\%) based on collection site. Values below the diagonal correspond to mosquitoes from group 1 compared with group 2 and correctly identified; values above the diagonal correspond to mosquitoes from group 2 compared with group 1 and correctly identified. P-value (parametric) $<0.0001$

\begin{tabular}{|c|c|c|c|c|c|c|c|c|c|c|c|c|}
\hline & & \multicolumn{11}{|c|}{ Group 2} \\
\hline & & CON-1 & $\mathrm{CON}-2$ & $\mathrm{CON}-3$ & CON-4 & CON-5 & INT-1 & INT-2 & INT-3 & INT-4 & URB-1 & URB-2 \\
\hline \multirow[t]{11}{*}{ Group 1} & CON-1 & - & 90 & 69 & 66 & 66 & 63 & 68 & 76 & 65 & 76 & 66 \\
\hline & $\mathrm{CON}-2$ & 84 & - & 73 & 66 & 83 & 83 & 72 & 83 & 62 & 66 & 80 \\
\hline & $\mathrm{CON}-3$ & 61 & 70 & - & 66 & 66 & 76 & 65 & 80 & 68 & 63 & 60 \\
\hline & $\mathrm{CON}-4$ & 61 & 83 & 73 & - & 63 & 76 & 65 & 76 & 55 & 60 & 73 \\
\hline & CON-5 & 46 & 90 & 69 & 60 & - & 80 & 68 & 70 & 79 & 60 & 63 \\
\hline & INT-1 & 46 & 86 & 73 & 66 & 73 & - & 55 & 73 & 48 & 70 & 70 \\
\hline & INT-2 & 53 & 80 & 65 & 60 & 70 & 73 & - & 63 & 65 & 56 & 73 \\
\hline & INT-3 & 76 & 93 & 88 & 66 & 63 & 70 & 65 & - & 58 & 70 & 70 \\
\hline & INT-4 & 46 & 80 & 65 & 60 & 63 & 50 & 62 & 56 & - & 53 & 56 \\
\hline & URB-1 & 38 & 66 & 73 & 63 & 56 & 63 & 51 & 70 & 48 & - & 63 \\
\hline & URB-2 & 69 & 86 & 76 & 76 & 63 & 63 & 75 & 56 & 65 & 76 & - \\
\hline
\end{tabular}


Table 3 Results of pairwise cross-validated species reclassification (\%) for the three urban areas. Values below the diagonal correspond to mosquitoes from group 1 compared with those from group 2 and correctly identified; values above the diagonal correspond to mosquitoes from group 2 compared with group 1 and correctly identified. $P$-value (parametric) $<0.0001$

\begin{tabular}{lllll}
\hline & & Group 2 & & \\
\cline { 3 - 5 } & & CON & INT & URB \\
\hline Group 1 & CON & - & 70 & 67 \\
& INT & 69 & - & 66 \\
& URB & 56 & 58 & - \\
\hline
\end{tabular}

[38]. A linear correlation analyses between Procrustes values and geographical distance $(\mathrm{km})$ was performed using PAST (v.3.16).

\section{Results}

\section{Wing shape}

The allometric effect in the populations tested was $9.5 \%$ $(P<0.0001)$ and was mathematically excluded from the subsequent analysis. When the populations in each urban build environment (CON, INT and URB) were considered as a metapopulation, wing geometric morphometrics showed a clear pattern of segregation in all analyses. There was a significant correlation between the wing shape variation (Procrustes) and the geographical distance between populations $\left(r=0.44 ; r^{2}=0.20 ; P<\right.$ 0.001 ) and the CVA revealed wing-shape variations in the Ae. aegypti populations considering both collection sites and population structuring induced by the different levels of urbanization in the collection areas (Fig. 2).

Cross-validated reclassification of the eleven populations yielded significantly high scores. Of 110 comparisons $(P<0.0001)$ only 6 had accuracies of less than $50 \%$, and 15 had accuracies of more than $80 \%$, indicating that there are significant differences in the wing shapes of these populations. The CON-2 population had significantly higher reclassification values (more than $80 \%$ reclassification accuracy) than all the other populations apart from URB-1, for which the reclassification score was $66 \%$. In contrast, the CON-1 population had the lowest reclassification scores, with four comparisons yielding scores of less than $50 \%$ (Table 2).

The reclassification scores based on urban build environments ranged from 56\% (URB vs CON) to 70\% (INT vs $\mathrm{CON}$ ), with an average of $64 \%$ indicating significant differences between metapopulations according to the urban build environment in which they had been collected (Table 3).

The NJ tree for all the populations shows that the INT populations segregated into a distinct branch, while there was partial overlap between the $\mathrm{CON}$ and URB populations $(P<0.005)$ (Fig. $3 a)$. The $\mathrm{CON}-1$ and CON-2 populations segregated into a single branch with 100 bootstrap value, indicating a high level of dissimilarity to the other populations. A second branch contained both populations from the most urbanized area, URB-1 and URB-2, and the CON-3 population. Furthermore, the subsequent analysis of metapopulations showed similar results, with INT segregated in a single branch with 100 bootstrap value (Fig. 3b). The complete segregation of the INT population found in the NJ analysis corroborates previous analyses and highlights the fact that they are dissimilar to the other populations.

Subsequent analysis considering the variation in populations from each urban build environment individually revealed significant dissimilarity between the CON populations, as shown by the complete segregation between
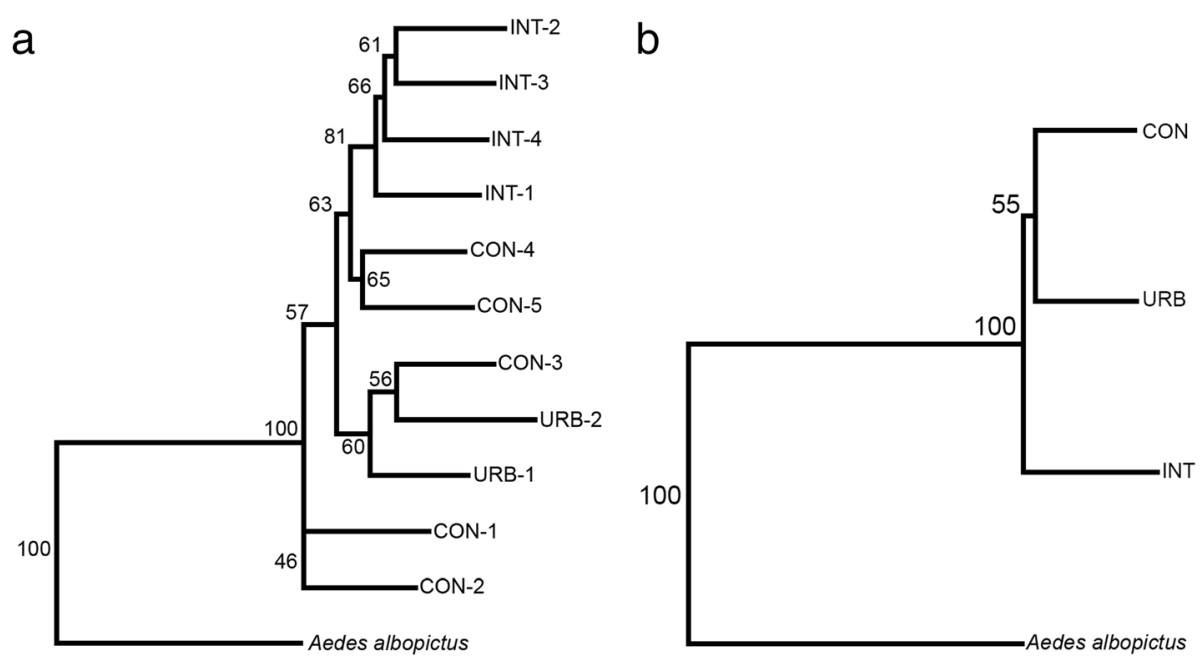

Fig. 3 Neighbor-joining trees based on Mahalanobis distance with 1000 bootstrap replicates. a For collection sites. $\mathbf{b}$ For urban build environment 


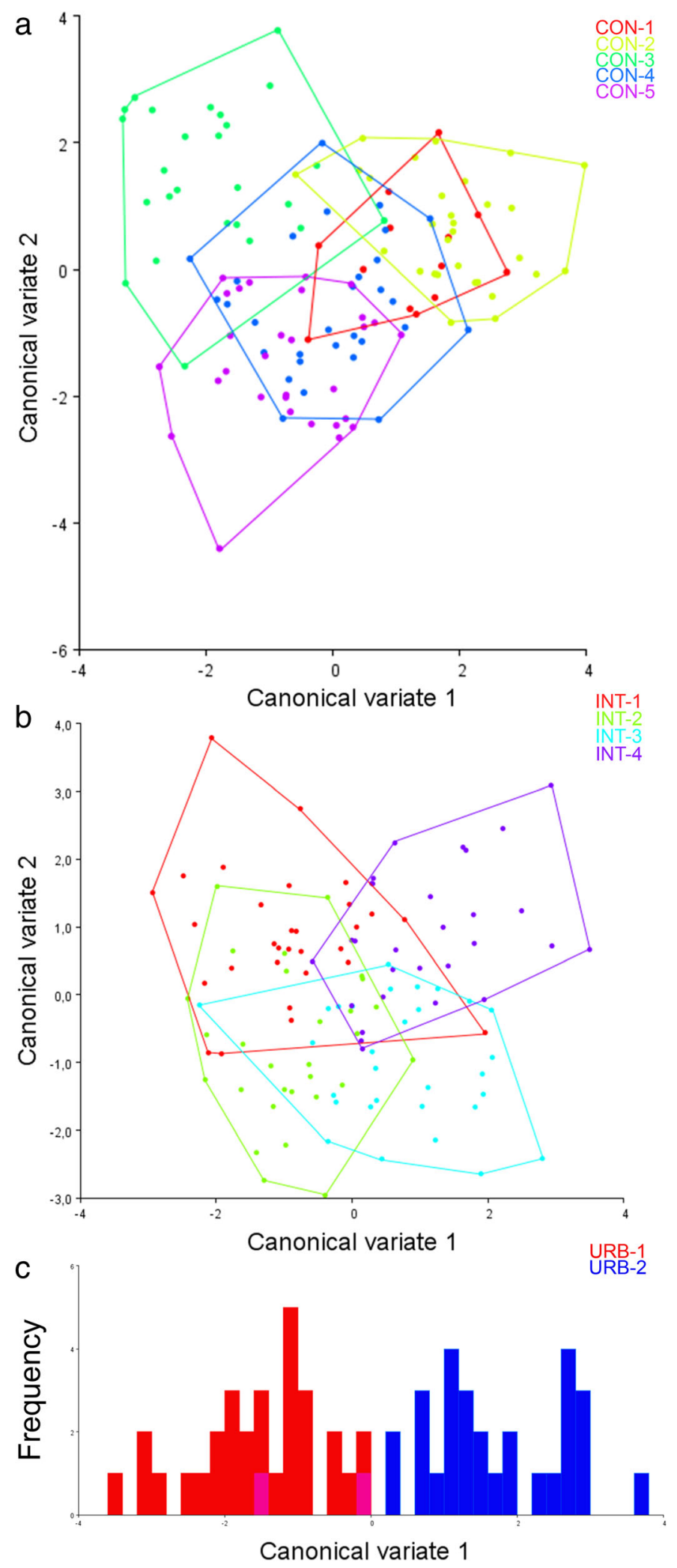

Fig. 4 Morphological space produced by CVA of wing shape of Aedes aegypti from the CON (a) and INT (b) areas and wing-shape diagram of first canonical variable for Aedes aegypti from the URB area (c) 


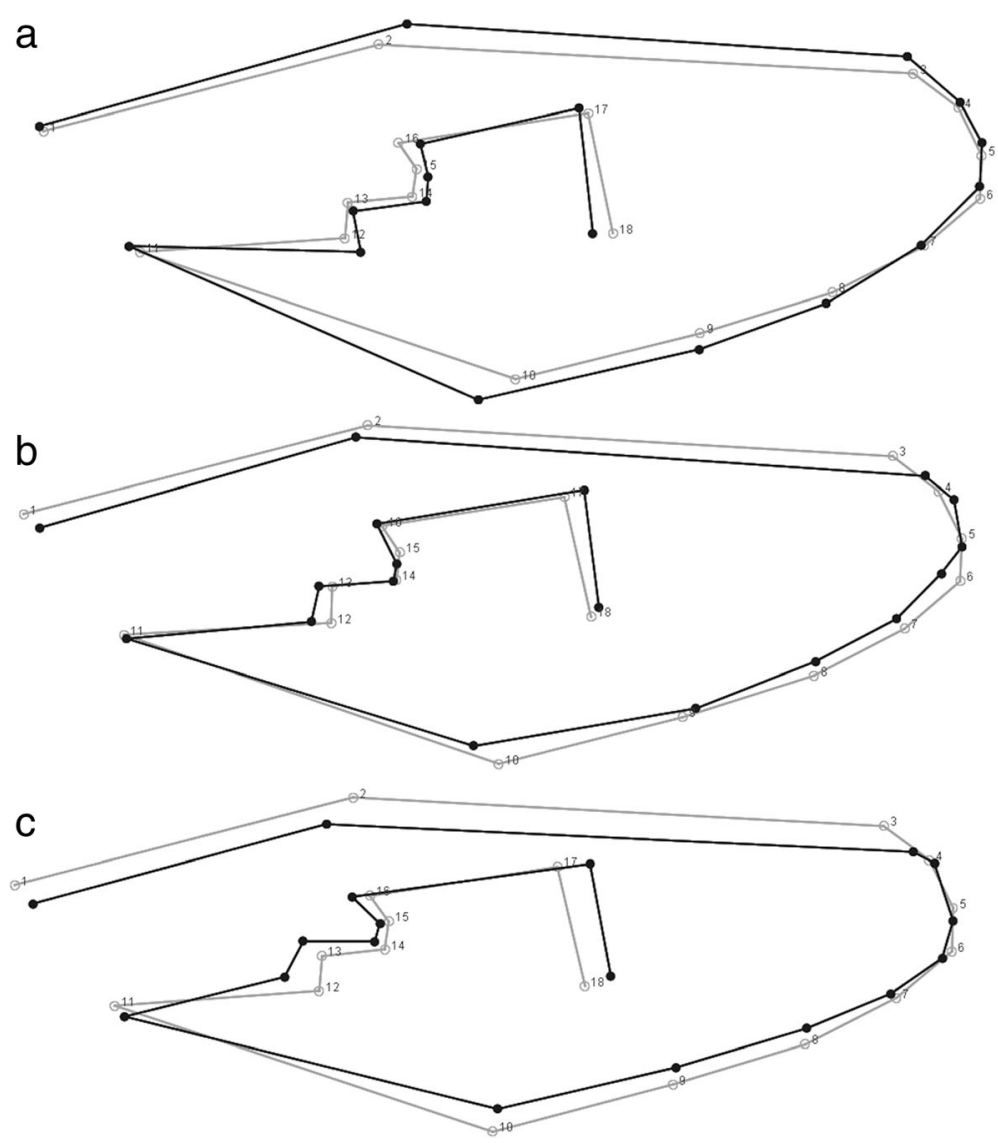

Fig. 5 Wireframe representation of shape variations between the three metapopulations. a CON vs INT; b CON vs URB; c URB vs INT

CON-2 and CON-5 and the significant partial segregation between $\mathrm{CON}-1$ and $\mathrm{CON}-3, \mathrm{CON}-1$ and $\mathrm{CON}-5$, and CON-2 and CON-3 in the CVA analysis (Fig. 4a). The INT populations occupied the largest area in the morphospace, displaying significant wing shape variations despite their proximity (Fig. 4b). The URB populations were almost completely segregated, as seen in the wing-shape diagram of the first canonical variable where only two wing shapes overlap, indicating a high degree of shape singularities despite the fact that they were collected in areas no more than $1 \mathrm{~km}$ apart (Fig. 4c).

Wing-shape variation within each metapopulation was also compared with the aid of a thin-plate spline and revealed that the INT metapopulation had the greatest variation in wing shape. The greatest variation between metapopulations was between URB and INT and between CON and INT, while the smallest was between CON and URB (Fig. 5).

\section{Discussion}

Aedes aegypti is an urban mosquito that is highly adapted to man-made changes and can be found in a wide range of urbanized environments. To thrive in these environments, it must cope with the intense selective pressures such changes bring about. This is reflected in our results, suggesting that different levels of urbanization may have been modulating the population dynamics of Ae. aegypti mosquitoes, agreeing with a previous study that used microsatellite markers to analyze Ae. aegypti populations from the same collection sites used in this study [39].

Populations from the environments with an intermediate level of urbanization had a significantly wider variety of wing shapes than the other populations. This phenomenon may be explained by the environmental heterogeneity in these areas, which have features of conserved and urbanized environments and a greater range of selective pressures, reflected in a wider variety of wing shapes. This hypothesis is supported by the results of the metapopulation analysis and the analysis of all the study populations individually. In contrast, environments with higher levels of urbanization exert stronger selective pressures, imposing a greater thermal amplitude variation resulting from the so-called "heat islands" [18], fewer resting places and availability of sugar sources, as well as pollution resulting from human action and mechanical removal of breeding sites. In 
addition, the frequent chemical interventions during control campaigns also account for the population structuring [39].

However, rather than increasing wing-shape variability, these stronger selective pressures increase the rate at which changes in wing shape occur, corroborating the findings of Louise et al. [22]. On the other hand, populations in conserved areas showed moderate wing-shape variation, which may be explained by the inherently more complex habitats with higher levels of biodiversity and density-dependent pressures [40-42]. This hypothesis is corroborated by a previous study for the same geographical region, in which the drivers for species richness and composition were found to be associated with urbanization processes [43].

The results of the cross-validated reclassification indicate a very significant variation in wing shape between the populations. Of 110 possible population comparisons, cross-validated reclassification scores for 15 were above $80 \%$ and only 6 below $50 \%$. Considering that these populations belong to a microgeographical region, these results indicate significant population structuring in Ae. aegypti as a result of urbanization processes.

Uncovering the mechanisms by which urbanization processes interact with mosquito populations, especially on a small scale, is of great epidemiological importance, particularly in the case of Ae. aegypti. A previous study conducted by Araujo et al. [44] found that urban heat islands have a higher incidence of dengue than other urban areas, indicating that variations in urbanization may be modulating dengue transmission. Similar findings were reported in a study by Lambrechts et al. [45], who found that temperature variations may influence dengue transmission patterns.

\section{Conclusions}

Areas with different levels of urbanization have different features and selective pressures. These pressures act on Ae aegypti, modulating the population structuring in this species. Furthermore, the fact that Ae. aegypti thrives in the urban environment, which provides a virtually unlimited number of breeding sites and human hosts for blood-feeding, may lessen the need for this species to migrate to new areas in search of food and breeding sites [46-48]. Finally, variations in environmental features, such as those caused by urbanization, appear to play an important role in the dynamics of Ae. aegypti populations. Wing geometric morphometrics was successfully used in this study to glimpse microevolutionary processes on Ae. aegypti populations in urban areas.

\section{Additional files}

Additional file 1: Table S1. Collection of immature Aedes aegypti according to breeding site. (DOCX $14 \mathrm{~kb}$ )

Additional file 2: Figure S1. UPGMA tree based on geographical distance $(\mathrm{km})$ for all populations. (TIF $1126 \mathrm{~kb}$ )

\begin{abstract}
Abbreviations
CON-1: Anhanguera Park; CVA: Canonical Variate Analysis; INT-2: Communication and Art School; CON: conserved areas; CON-2: Eucalipto Park; CON-

3: Independência Park; INT: Intermediate areas; URB-2: Medicine School; NJ: Neighbor-joining; INT-3: Physics Institute; CON-4: Piqueri Park; CON5: Previdência Park; URB-1: Public Health School; INT-1: University of São Paulo Student Accommodation; URB: urbanized areas; INT-4: Veterinary School
\end{abstract}

\section{Acknowledgements}

The authors would like to thank Rafael de Oliveira Christe for kindly providing the Aedes albopictus population used in the analysis.

\section{Funding}

This study was supported by the State of São Paulo Research Foundation (FAPESP) (grant 2013/15313-4). RWS is the recipient of an MSc fellowship from FAPESP (2015/01172-5).

\section{Availability of data and materials}

All data generated or analyzed during this study are included in this published article and its additional files.

\section{Authors' contributions}

ABBW and MTM designed the study. RWS and MMCSLD carried out the experiments and data analysis. RWS, MTM and ABBW drafted the manuscript and critically revised it. All authors read and approved the final manuscript.

\section{Ethics approval and consent to participate}

The study was approved by the Ethics Committee of the University of São Paulo, Brazil, and collection permits were provided by the Department of the Environment and Green Areas, São Paulo City, Brazil.

Consent for publication

Not applicable.

\section{Competing interests}

The authors declare that they have no competing interests.

\section{Publisher's Note}

Springer Nature remains neutral with regard to jurisdictional claims in published maps and institutional affiliations.

\section{Author details}

${ }^{1}$ Departamento de Epidemiologia, Faculdade de Saúde Pública, Universidade de São Paulo, São Paulo, Brazil. ${ }^{2}$ Department of Public Health Sciences, Miller School of Medicine, University of Miami, Miami, FL, USA.

Received: 11 June 2018 Accepted: 16 October 2018

Published online: 26 October 2018

\section{References}

1. Bhatt S, Gething PW, Brady OJ, Messina JP, Farlow AW, Moyes CL, et al. The global distribution and burden of dengue. Nature. 2013:496:504-7.

2. Brady OJ, Gething PW, Bhatt S, Messina JP, Brownstein JS, Hoen AG, et al. Refining the global spatial limits of dengue virus transmission by evidence-based consensus. PLoS Negl Trop Dis. 2012;6:e1760.

3. World Health Organization. Dengue and severe dengue. WHO Fact Sheets. 2012. www.who.int/mediacentre/factsheets/fs117/en/index.htm.

4. Kraemer MUG, Sinka ME, Duda KA, Mylne AQN, Shearer FM, Barker CM, et al. The global distribution of the arbovirus vectors Aedes aegypti and Ae. albopictus. Elife. 2015:4:e08347. 
5. Higa Y. Dengue vectors and their spatial distribution. Trop Med Health. 2011;39:517-27.

6. Wilkerson RC, Linton Y-M, Fonseca DM, Schultz TR, Price DC, Strickman DA. Making mosquito taxonomy useful: a stable classification of tribe Aedini that balances utility with current knowledge of evolutionary relationships. PLoS One. 2015;10:e0133602.

7. Jaenisch T, Tam DTH, Kieu NTT, Van Ngoc T, Nam NT, Van Kinh N, et al. Clinical evaluation of dengue and identification of risk factors for severe disease: protocol for a multicentre study in 8 countries. BMC Infect Dis. 2016;16:120.

8. Pialoux G, Gaüzère B-A, Jauréguiberry S, Strobel M. Chikungunya, an epidemic arbovirosis. Lancet Infect Dis. 2007;7:319-27.

9. Hayes EB. Zika virus outside Africa. Emerg Infect Dis. 2009;15:1347-50

10. Frierson JG. The yellow fever vaccine: a history. Yale J Biol Med. 2010;83:77-85.

11. Staples JE, Breiman RF, Powers AM. Chikungunya fever: an epidemiological review of a re-emerging infectious disease. Clin Infect Dis. 2009;49:942-8.

12. Malone RW, Homan J, Callahan MV, Glasspool-Malone J, Damodaran L, Schneider ADB, et al. Zika virus: medical countermeasure development challenges. PLoS Negl Trop Dis. 2016;10:e0004530.

13. Consoli RAGB, Lourenço-de-Oliveira R. Principais Mosquitos de Importância Sanitária No Brasil, vol. 11. Rio de Janeiro: Editora FIOCRUZ; 1994.

14. Forattini OP. Culicidologia Médica, vol. 2. São Paulo: Editora da Universidade de São Paulo; 2002.

15. Liebman KA, Stoddard ST, Reiner RC, Perkins TA, Astete H, Sihuincha M, et al. Determinants of heterogeneous blood feeding patterns by Aedes aegypti in lquitos, Peru. PLoS Negl Trop Dis. 2014;8:e2702.

16. Cardo MVM, Rosín P, Carbajo AE, Vezzani D. Artificial container mosquitoes and first record of Aedes aegypti in the islands of the Paraná Lower Delta, Argentina. J Asia Pac Entomol. 2015;18:727-33.

17. Dhar-Chowdhury P, Haque CE, Lindsay R, Hossain S. Socioeconomic and ecological factors influencing Aedes aegypti prevalence, abundance, and distribution in Dhaka, Bangladesh. Am J Trop Med Hyg. 2016;94:1223-33.

18. Townroe S, Callaghan A. British container breeding mosquitoes: the impact of urbanisation and climate change on community composition and phenology. PLoS One. 2014;9:e95325.

19. Matthys B, N'Goran EK, Koné M, Koudou BG, Vounatsou P, Cissé G, et al. Urban agricultural land use and characterization of mosquito larval habitats in a medium-sized town of Côte d'Ivoire. J Vector Ecol. 2006;31:319-33.

20. Farajollahi A, Fonseca DM, Kramer LD, Kilpatrick AM. "Bird biting" mosquitoes and human disease: a review of the role of Culex pipiens complex mosquitoes. Infect Genet Evol. 2011;11:1577-85.

21. Scott TW, Takken W. Feeding strategies of anthropophilic mosquitoes result in increased risk of pathogen transmission. Trends Parasitol. 2012;28:114-21.

22. Louise C, Vidal PO, Suesdek L. Microevolution of Aedes aegypti. PLoS One. 2015;10:e0137851.

23. Vidal PO, Carvalho E, Suesdek L. Temporal variation of wing geometry in Aedes albopictus. Mem Inst Oswaldo Cruz. 2012;107:1030-4.

24. Wilke ABB, Christe R de O, Multini LC, Vidal PO, Wilk-da-Silva R, de Carvalho $\mathrm{GC}$, et al. Morphometric wing characters as a tool for mosquito identification. PLoS One. 2016;11:e0161643.

25. Christe R de O, Wilke ABB, Vidal PO, Marrelli MT. Wing sexual dimorphism in Aedes fluviatilis (Diptera: Culicidae). Infect Genet Evol. 2016;45:434-6.

26. Gaspe MS, Schachter-Broide J, Gurevitz J, Kitron U, Gürtler RE, Dujardin JP. Microgeographic spatial structuring of Triatoma infestans (Hemiptera: Reduviidae) populations using wing geometric morphometry in the Argentine Chaco. J Med Entomol. 2012;49:504-14.

27. Motoki MT, Suesdek L, Bergo ES, Sallum MAM. Wing geometry of Anopheles darlingi Root (Diptera: Culicidae) in five major Brazilian ecoregions. Infect Genet Evol. 2012;12:1246-52.

28. Carvalho GC, Vendrami DP, Marrelli MT, Wilke ABB. Wing variation in Culex nigripalpus (Diptera: Culicidae) in urban parks. Parasit Vectors. 2017;10:423.

29. Carvajal TM, Hernandez LFT, Ho HT, Cuenca MG, Orantia MC, Estrada CR, et al. Spatial analysis of wing geometry in dengue vector mosquito, Aedes aegypti (L.) (Diptera: Culicidae), populations in Metropolitan Manila, Philippines. J Vector Borne Dis. 2016;53:127-35.

30. Henry A, Thongsripong P, Fonseca-Gonzalez I, Jaramillo-Ocampo N, Dujardin JPP. Wing shape of dengue vectors from around the world. Infect Genet Evol. 2010;10:207-14.

31. Jian Y, Silvestri S, Brown J, Hickman R, Marani M. The temporal spectrum of adult mosquito population fluctuations: conceptual and modeling implications. PLoS One. 2014;9:e114301.
32. Descloux E, Mangeas M, Menkes CE, Lengaigne M, Leroy A, Tehei T, et al. Climate-based models for understanding and forecasting dengue epidemics. PLoS Negl Trop Dis. 2012;6:e1470.

33. Rodrigues MDM, Marques GRAM, Serpa LLN, Arduino MDB, Voltolini JC, Barbosa GL, et al. Density of Aedes aegypti and Aedes albopictus and its association with number of residents and meteorological variables in the home environment of dengue endemic area, São Paulo, Brazil. Parasit Vectors. 2015;8:115.

34. Natal D, Marucci D. Aparelho de sucção tipo aspirador para captura de mosquitos. Rev Saude Publica. 1984;18:418-20.

35. Rohlf FJ. tpsDig, digitize landmarks and outlines, version 2.05. Stony Brook, NY: Department of Ecology and Evolution, State University of New York; 2006.

36. Chintapalli RTV, Hillyer JF. Hemolymph circulation in insect flight appendages: physiology of the wing heart and circulatory flow in the wings of the mosquito Anopheles gambiae. J Exp Biol. 2016;219:3945-51.

37. Klingenberg CP. MorphoJ: An integrated software package for geometric morphometrics. Mol Ecol Resour. 2011;11:353-7.

38. Hammer $\varnothing$, Harper DATT, Ryan PD. PAST: Paleontological Statistics Software Package for education and data analysis. Palaeontol Electron. 2001:4:1-9.

39. Wilke ABB, Wilk-da-Silva R, Marrelli MT. Microgeographic population structuring of Aedes aegypti (Diptera: Culicidae). PLoS One. 2017;12:e0185150.

40. Chaves LF, Morrison AC, Kitron UD, Scott TW. Nonlinear impacts of climatic variability on the density-dependent regulation of an insect vector of disease. Glob Chang Biol. 2012;18:457-68.

41. Ceretti-Júnior W, Medeiros-Sousa AR, Multini LC, Urbinatti PR, Vendrami DP, Natal $D$, et al. Immature mosquitoes in bamboo internodes in municipal parks, City of São Paulo, Brazil. J Am Mosq Control Assoc. 2014;30:268-74.

42. Ceretti-Junior W, de Oliveira Christe R, Rizzo M, Strobel RC, de Matos Junior MO, de Mello MHSH, et al. Species composition and ecological aspects of immature mosquitoes (Diptera: Culicidae) in bromeliads in urban parks in the City of Sao Paulo Brazil. J Arthropod Borne Dis. 2016;10:102-12.

43. Medeiros-Sousa AR, Fernandes A, Ceretti-Junior W, Wilke ABB, Marrelli MT. Mosquitoes in urban green spaces: using an island biogeographic approach to identify drivers of species richness and composition. Sci Rep. 2017;7:17826.

44. Araujo RV, Albertini MR, Costa-da-Silva AL, Suesdek L, Franceschi NCS, Bastos NM, et al. São Paulo urban heat islands have a higher incidence of dengue than other urban areas. Brazilian J Infect Dis. 2015;19:146-55.

45. Lambrechts L, Paaijmans KP, Fansiri T, Carrington LB, Kramer LD, Thomas MB, Scott TW. Impact of daily temperature fluctuations on dengue virus transmission by Aedes aegypti. Proc Natl Acad Sci USA. 2011;108:7460-5.

46. Wilke ABB, Vasquez C, Mauriello PJ, Beier JC. Ornamental bromeliads of Miami-Dade County, Florida are important breeding sites for Aedes aegypti (Diptera: Culicidae). Parasit Vectors. 2018;11:283.

47. Chitolina RF, Anjos FA, Lima TS, Castro EA, Costa-Ribeiro MCV. Raw sewage as breeding site to Aedes (Stegomyia) aegypti (Diptera, Culicidae). Acta Trop. 2016;164:290-6.

48. Ramasamy R, Surendran SN, Jude PJ, Dharshini S, Vinobaba M. Larval development of Aedes aegypti and Aedes albopictus in peri-urban brackish water and its implications for transmission of arboviral diseases. PLoS Negl Trop Dis. 2011;5:e1369.

\section{Ready to submit your research? Choose BMC and benefit from:}

- fast, convenient online submission

- thorough peer review by experienced researchers in your field

- rapid publication on acceptance

- support for research data, including large and complex data types

- gold Open Access which fosters wider collaboration and increased citations

- maximum visibility for your research: over $100 \mathrm{M}$ website views per year

At $\mathrm{BMC}$, research is always in progress.

Learn more biomedcentral.com/submissions 